\title{
Sexual behaviour and inheritance rights among HIV- positive women in Abia State, Nigeria
}

\author{
E.E. ENWEREJI \\ College of Medicine, Abia State University, Uturu, Abia State, Nigeria \\ E-mail: hersng@yahoo.com
}

\begin{abstract}
In developing countries, culture favours males for economic ventures more than females. There is evidence that allowing HIV positive women inheritance rights will mitigate negative economic consequences of HIV/AIDS and other related risks. This study aimed to examine the extent to which HIV positive women have access to family resources in Abia State, Nigeria. Data collection instruments were questionnaire, focus group discussion and interview guides using 98 HIV positive women in network of people living with HIV/AIDS. Five key informants were also interviewed to authenticate women's responses. Results showed that $85(86.7 \%)$ of the women were denied rights to family resources. Thirty-eight (64.4\%) of them had negative relationship with their family members for demanding their husbands' property. Because of limited financial assistance, the women took two types of risks in order to survive in the communities. Twenty-five women $(25.5 \%)$ earned their livelihood by acting as hired labourers to others in the farm. More that half (55.1\%) of the HIV positive women were practicing unprotected sex. Although as high as $79.6 \%$ of women were aware of risks of unprotected sex, $54(55 \%)$ of them practised it. The commonest reason for taking the risk was sex partners' dislike for condom use. The high proportion of HIV positive women who were denied access to family resources, could suggest lack of care and support. If this denial continues, Government's efforts to reduce HIV prevalence would yield no significant result. There is therefore need for organized community education programme that emphasizes the benefits of empowering women living positively with HIV/AIDS economically.
\end{abstract}

Key words: inheritance rights, HIV/AIDS, sexual behaviour, Nigeria

\section{Introduction}

One of Nigeria's greatest challenges is improving the lives of women living positively with HIV/AIDS. In Nigeria, 5\% among women attending antenatal care services are infected with HIV (FMH, 2000). However, their economic empowerment has not been given high priority by researchers, decision and policy makers. There is growing evidence that allowing women, especially HIV positive women, inheritance rights to family resources will mitigate negative economic consequences of HIV/AIDS and reduce poverty, and other related risk factors (Zulu et al., 2002; Whiteside 2002; UN 2004). This is necessary because women's lack of economic empowerment is among the key factors in the spread of HIV/AIDS (World Bank 2003; FAO, 2002). Property ownership is a source of security, means of livelihood and a quick source of wealth or capital by which additional economic resources are leveraged in developing countries (Umeasiegbu, 1977; Swaminathan et al., 2007).

In Nigeria, culturally women are not allowed to own resources that would allow them to be at par with men economically. It is this premise that encouraged widespread exclusion of women from access to, ownership and/or control of resources such as land, housing, livestock and others (Deere \& Leon, 2001). In the past, a widow was allowed to remain in her husband's homes where a brother in-law might inherit her and provide for her economic and social needs (Anyanwu et al., 1999). Nowadays, the devastating effects of HIV/AIDS, changes in social values, economic hardship, and the desire to possess scarce resources of the deceased, have contributed to ejection of widows from matrimonial homes. Such acts are likely to expose them to risky sexual behaviours and hence transmission of HIV (Odusanya \& Alakija, 2004). The economic burdens of HIV/AIDS that have reduced household income by $80 \%$, food consumption by $15-30 \%$ and primary school enrolment by $20-40 \%$ (Drimie, 2002) constitute need to encourage women especially in developing countries, to have access to family resources.

HIV positive women deserve good health care and nutrition. Poor understanding of the basic health care needs of HIV positive women could create further the chances of discriminating against women in terms of rights to inherit family resources (Deere \& Leon 2001). This study aimed to investigate the extent to which HIV positive women, especially the widowed, amidst stringent cultural practices, are allowed access to family resources to enable them generate finance to care for themselves and their dependants. Specifically, this study aimed to: (i) determine the extent to which traditional rulers support economic empowerment of HIV positive women (ii) identify types of relationship that exist between HIV positive women and their relatives, and (iii) examine the risks HIV positive women take to survive in communities. 


\section{Materials and Methods}

\section{Study area}

The study was carried out in Abia State in southeastern Nigeria. The State comprises 17 local government areas with a common language. Majority of the communities in Abia State practice patrilineal system of inheritance. In terms of marriage, the practice is exogamy. A woman, on marriage, leaves her own descent to live with that of the man. This practice makes it impossible for a woman to inherit immovable resources like land, house and others. However, she inherits these through her male children if she has any. If she has no male child, someone in the family would act as 'loco filial'" otherwise, inheritance could be through her brothers.

\section{Data collection}

Data collection instruments were questionnaire, focus group discussion and interview guides. The questionnaire comprised of open-ended and closed-ended questions. The questionnaire was administered for those who cannot write and self-administered for those who can write. The questions sought information on types of relationship the women enjoyed with their family members, place of residence, education, inheritance rights, means of livelihood and risks the women took in the communities. Interview with structured questions was used as a means of uncovering some information that respondents may not be willing to release at group level. The interview schedule collected information on cohabitation, sexual behaviour and future plans for marrying and/or re-marrying as well as raising children. This method was termed necessary because of the sensitive nature of study.

The questions in the focus group discussion contained unstructured questions which sought information on marital life, inheritance rights, and opportunities for financial assistance in the family. Twelve focus group discussions comprising 7-9 HIV positive women were organized with the help of three trained research assistants. The women were grouped by age, marital status, cohabitation and employment status. A questionnaire with open-ended questions was used to gather information from the traditional rulers (as key informants). Information sought included inheritance rights, economic empowerment, and knowledge of problems of the women. For uniformity, the key informant guide was self- administered. Male traditional rulers were randomly drawn from five closest communities. They were included in the study so as to authenticate the responses obtained from the women. Traditional rulers are custodians of culture and would be in the best position to provide valid information regarding what obtains in the society. Moreover, traditional rulers are close to Governments and are considered useful in lobbying Government to enact policies that would positively change inheritance rights of women.

\section{Data analysis}

Data were analyzed both qualitatively and quantitatively. Results of focus group discussion were grouped into themes and were translated and transcribed by three trained research assistants.

\section{Ethical consideration}

The University Ethical Committee vetted and approved the study before its commencement. Following this approval, permission to conduct the study was obtained from the President of network of people living positively with HIV/AIDS (PLWHA) as well as from the female members of the network in the State. A request was also made to participants for permission to tape-record the session and this was guaranteed. In addition, a written permission to conduct the study was requested and obtained from traditional rulers in the five communities included in the study.

\section{Results}

\section{Background information of HIV positive women}

A total of $98 \mathrm{HIV}$ positive women were included in this study. All of them were Christians. The average age of women was 22 years; 29 (29.5\%) had primary school education, $34(34.7 \%)$ had secondary school education, $21(21.4 \%)$ and $14(14.3 \%)$ had no formal education. Eighty-three (84.7\%) were Igbos, while 15 (15.3\%) were from Ibibio, Yoruba and Hausa tribes. About two-thirds of them, 64 (65.3\%) were widowed, $20(20.4 \%)$ were married while 14 (14.3\%) were single. Out of those married, $8(8.2 \%)$ of them cohabited with their husbands, while $12(12.2 \%)$ of them were divorced and/or separated. Of the 64 widowed, 48 (49\%) were forced back to their natal homes, while 16 $(16.3 \%)$ were inherited by relations of their husbands. For the singles, $6(6.1 \%)$ were about getting married while the rest were hoping to get married soon. Of the population of HIV positive women, only 16 (15.3\%) were employed and $82(83.7 \%)$ were unemployed. Sixty-one respondents (62.2\%) complained of lack of financial assistance from relations. In all, 38 (37\%) and $60(63 \%)$ of the HIV positive women lived in urban and rural areas, respectively. 


\section{Inheritance rights}

The majority of HIV positive women including widows were denied rights to inherit family resources. A total of $85(86.7 \%)$ of the HIV positive women said they had no access to family resources like land, house and car. Reports from focus group discussion with HIV positive women showed that some of their children dropped out of school for inability to pay school fees. When asked about their experiences, a good number of them reported having similar encounters like those in the rural areas, showing that HIV positive women both in urban and rural areas experienced limits on their access to family resources. Fifty-eight (59.2\%) of the women felt that if allowed access to family assets, that they could easily raise money to carter for their children's needs. The women's greatest need was how to raise money to purchase anti-retroviral drugs which costed US\$40-\$95 per month. Quoting the responses of two HIV positive women: "We were inherited by our brothers' in-law yet they do not provide for our financial needs. When we asked for assistance, they booed at us". This indicates lack of financial assistance from family members.

\section{Relationships between HIV positive women and family members}

Result of focus group discussion showed that majority of the HIV positive women especially the widowed had horrifying experiences. Negative attitudes and you will deny you financial assistance. Men are generally wicked. They purposely would not provide your needs. If you complain they will label you as a bad woman. The problem will be more if you venture to disclose your HIV status to them. They will stigmatize and abandon you".

Widows especially those who refused to be inherited complained of being chastised for demanding husbands' property and/or assistance. Using the reports from three widows: "We have six children, yet we lost our husbands'property to brothers' in-law barely one month after the death of our husbands. When we complained, we were chased out of our matrimonial houses".

The result of the quantitative data confirmed the negative relationship as reported by the women during the focus group discussion. The commonest reason 38 (64.4\%) was their demand for husbands' property (Table 1$)$.

The risk of being chastised among women cuts across all marital statuses, including the married 7 (7.1\%), single $4(4.1 \%)$, and widowed $48(49 \%)$. As high as $59(60.2 \%)$ of them were chastised but this was more among widows $48(49 \%)$ showing that the more widowed HIV positive women were, the more they were chastised, while the more single they were, the less they were chastised.

\section{Women's risk behaviours}

Two types of risks that HIV positive women took

Table 1: Reasons for family members' negative attitude to HIV positive women $(\mathrm{N}=59)$

\begin{tabular}{lcc}
\hline Reason & Number of respondents* & Per cent \\
\hline Demanding husbands property & 38 & $64.4 \%$ \\
Refusing to be inherited & 22 & $37.3 \%$ \\
Knowing one's HIV status & 29 & $49.2 \%$ \\
Asking for financial assistance & 36 & $61.0 \%$ \\
Not having male children & 19 & $32.2 \%$ \\
Being sickly & 11 & $18.6 \%$ \\
Refusing to have sex & 20 & $33.9 \%$ \\
Being accused of killing husband & 15 & $25.4 \%$ \\
\hline
\end{tabular}

${ }^{*}$ Multiple choices

lack of family support to HIV positive women were some of the major barriers found to affect access to family resources. When the women were asked about opportunities for rights to assets for those who were inherited by husband's relation, four of them said: "We are not happy. This disease is more than a poison. Family members including the person who inherited were identified. Twenty-five (25.5\%) of the women earned their livelihood by acting as hired labourers to others in the farm, a risk that could easily wear them down health-wise. All 98 women gave response to the question on their sexual practice. More than half $(55.1 \%, \mathrm{~N}=54)$ of HIV positive women had sex without condom. Only 20 (20.4\%) had ever used condoms during sex; of these, 11 were from urban and 9 from 
rural areas. About a quarter (24.5\%) did not have sex during the reporting period; more women from the rural $(14.3 \%)$ than from urban $(10.2 \%)$ areas did not have sex. Although both women in urban and rural areas reported that they had sex without condom, this practice was more common with women $(37.8 \%)$ in the rural area than those (17.7\%) in urban area.

Women's perceived risks of HIV transmission

Considering the number of HIV positive women 54
Views of traditional rulers on economic empowerment of HIV positive women

The five traditional rulers interviewed had negative views about allowing women especially HIV positive women including those widowed, the opportunity to inherit family resources. The common view was that encouraging women to inherit family assets would make them obstinate and that this was against the culture. Using the words of the traditional rulers, 'no organized society would allow women right to im-

Table 2: Women and frequency of response on the perceived risks of HIV infection

\begin{tabular}{lllllll}
\hline Perceived risk & $\begin{array}{l}\text { Widows } \\
\text { (not inherited) }\end{array}$ & $\begin{array}{l}\text { Widows } \\
\text { (inherited) }\end{array}$ & $\begin{array}{l}\text { Married } \\
\text { (cohabiting) }\end{array}$ & $\begin{array}{l}\text { Married } \\
\text { (not cohabiting) }\end{array}$ & Single & Total \\
\hline Great risk & $23(23.5 \%)$ & $4(4.1 \%)$ & $2(2 \%)$ & $4(4.1 \%)$ & $5(5.1 \%)$ & $38(38.8 \%)$ \\
Moderate risk & $12(12.2 \%)$ & $2(2 \%)$ & $3(3.1 \%)$ & $3(3.1 \%)$ & $2(2 \%)$ & $22((22.4)$ \\
Low risk & $5(5.1 \%)$ & $7(7.1 \%)$ & $1(1 \%)$ & $2(2 \%)$ & $3(3.1 \%)$ & $18(18.4 \%)$ \\
No risk & $8(8.2 \%)$ & $3(3.1 \%)$ & $2(2 \%)$ & $2(2 \%)$ & $4(4.1 \%)$ & $20(20.4)$ \\
Total & $48(49 \%)$ & $16(16.3 \%)$ & $8(8.2 \%)$ & $12(12.2 \%)$ & $14(14.3 \%)$ & $98(100 \%)$ \\
\hline
\end{tabular}

(55.1\%) who had sex without condom, the extent to which they perceived their action as a risk for HIV infection was examined. To assess this, participants were asked to rate having sex without condom as great, moderate, low, or no risk for HIV infection. The women's responses were matched with their marital status. As high as $79.6 \%$ of the respondents were aware that having sex without condom constituted high risks for HIV infection. Twenty-three (23.5\%) of the widows who were not inherited were more aware of the risk of unprotected sex than others (Table 3 ). There was need to ascertain reasons the women had for taking the risk of unprotected sex despite their high knowledge of the risk. The commonest reason (87\%) HIV positive women had for their action was that their sex partners disliked condom use. movable property like land, house and others '. They stressed that women are subordinates to men and that whatever economic assets they acquired should be manned by men. Majority of the traditional rulers felt that it would be a taboo to allow females the opportunity of inheriting family resources when there are males in the family. Their belief was that men as breadwinners should keep custody of all resources so as to plan how to disburse them for the benefit of all family members. They argued that assets procured by women should be handed over to the men for safekeeping as the culture stipulates.

Some of the traditional rulers expressed that the main problem of women was that culture demands that they live in joint households where elders are key decision makers in cultural issues and that these

Table 3: Number of respondent (\%) and their reasons for unprotected sex $(\mathrm{N}=54)$

\begin{tabular}{lll}
\hline Reasons & Number & Percent \\
\hline Male partners dislike condom use & 47 & $87 \%$ \\
Ashamed to negotiate condom use & 19 & $35.2 \%$ \\
Do not have condom & 13 & $24.0 \%$ \\
Wants to have babies & 12 & $15.4 \%$ \\
Needs financial assistance & 39 & $72.2 \%$ \\
Fear of being beaten & 17 & $31.5 \%$ \\
Would not like to be termed promiscuous & 21 & $38.9 \%$ \\
Do not want people to know my sero-status & 27 & $50.0 \%$ \\
No reason & 9 & $16.7 \%$ \\
\hline
\end{tabular}

* Multiple responses 
elders exercise pressure on men to exert their ownership rights in family resources. The traditional rulers were of the feelings that since elders were more supportive to men than women, that it would be difficult to convince them to act otherwise. Finding on non-supportive nature of elders to women was also confirmed by reports from HIV positive women during focus group discussion. The women reiterated that usually, elders fail to consider them as potential heirs when making decisions in the family.

\section{Traditional rulers' knowledge of immediate problems of HIV positive women}

The traditional rulers' overall knowledge of health and nutritional problems of HIV positive women was poor. A good number of the traditional rulers felt that availability of food, especially the staple food 'gari' (cassava product) was the immediate problem of individuals including HIV positive women. Rice, beans and yam were regarded as extra luxury items, which may not be afforded by all. However, some of the traditional rulers felt giving high protein food to HIV positive women as luxury stressing that with the harsh economic situation, no individual in the rural areas should be expected to afford balanced food for family members. In the words of the traditional rulers, 'most families at times, are unable to afford two meals a day for their family members. Telling such individuals to treat HIV positive women differently would not be realistic'. They saw no need to suggest preparing HIV positive women's menu differently from family menu. In terms of the health problems of HIV positive women, the traditional rulers saw no difference between the health of HIV positive women and that of others. Majority of the traditional rulers were of the view that 'women are usually known for regular spells of ill-health and that women living positively with HIV/AIDS should not be exception'.

Though the traditional rulers had some knowledge of the needs of HIV positive women, they were not aware that HIV positive women need balanced diet and regular medical attention. They saw no relationship between balanced meal and coping with the impacts of HIV/AIDS. They believed that HIV is associated with 'sex' and bad behaviour against the social norms of the land, and therefore the affected women were not entitled to good treatment from people. One important finding from the interview with the traditional rulers was their lack of knowledge of women who were HIV positive in their communities. This lack of knowledge portrays that those who are HIV positive rarely disclose their sero-status in the communities.

\section{Discussion}

The fact that a high proportion of HIV positive women $85(86.7 \%)$ were denied access to family resources indicates lack of care and support. The finding on lack of care and support was supported by the responses of the traditional rulers who pledged ignorance of the needs of the HIV positive women. Lack of support was also shown by the proportion of women who were chased out of their family homes for requesting for financial assistance. The finding on lack of care and support agrees with the observations by Deere $\&$ Leon (2001) in Latin America and Izugbara \& Modo (2007) in Nigeria. However, our findings are at variance with that of Whiteside (2002) who reported an increased care and support for people living positively with HIV/AIDS.

Chasing out HIV positive women and/or denying them financial assistance is arguably a kind of domestic violence. However, it was not clear the extent to which traditional rulers as custodians of culture discouraged this violence on HIV positive women. In the present study, only a few widows were inherited and those inherited also complained of lack of access to their husbands' resources, showing that inheritance neither guaranteed possession of husbands' property nor financial assistance from husband's relations. This finding agrees with the views of Albertyn (2000) that due to economic scarcity, many males do not care for widows.

Although a good proportion of HIV-positive women were aware that unprotected sex could expose individuals to HIV infection, yet, more than half of them still engaged in unprotected sex showing that knowledge of HIV transmission is not a guarantee to encourage HIV prevention. Similar findings have been reported elsewhere (Anyanwu et al., 1999; Gruskin, 1995; Madise, 2007). The fact that men took all major decisions in the home including that of condom use justifies the subordinate role of women in decision-making even that of sexual relationships. This subordinate role of women in decision-making is one of the major contributing factors that influenced risks of unprotected sex among HIV positive women in our study.

Denying HIV positive women access to family resources could have devastating effects on their economic empowerment, and sexual life. This denial could expose them to poverty, risky sexual behaviours, pervasive marginalization, and others. If this denial to family resources continues, Government's efforts to empower women economically so as to reduce HIV prevalence would yield no significant result 
unless policies are enacted to encourage women's access to family resources. According to Gruskin \& Wakhweya (1997) the prevention of HIV transmission and quality care for people with HIV/AIDS requires a rectification of the adverse effect of social discrimination against groups of people vulnerable to the infection.

It is the right time that the gap between HIV/AIDS policies and human rights, the gap between HIV/ AIDS-related laws and practices and human rights, and strategies for action are discussed and implemented in countries where women rights of inheritance is a problem. It is therefore important that the Government of Nigeria should initiate community education programme to enlighten individuals on the benefits of empowering HIV positive women financially.

Received 28 August 2007

Revised 23 January 2008

Accepted 25 February 2008

\section{References}

Albertyn, C. (2000) Using Rights and the Law to Reduce Women's Vulnerability to HIV 5 (4) Canadian HIV/AIDS Policy Law Review 72. http://www.aidslaw.ca/Maincontent/otherdocs/Newsletter/newsletter.htm

Anyanwu , F.C., Udo, C.O. \& Okpala, P.N. (1999) Socio- cultural practices as correlates of psychological disposition of widows in Imo State. Nigerian School Journal 1 and 2, 66-71.

Deere, C.D. \& Leon, M. (2001) Empowering Women: Land and Property Rights in Latin America, Pittsburgh: University Press

Drimie, S. (2002) The impact of HIV/AIDS on land: Case Studies from Kenya, Lesotho and South Africa. Synthesis Report for the FAO Southern African Regional Office. Pretoria: Human Science Research Council.

FAO (2002) Food and Agriculture Organization. Gender and access to land. FAO Land Tenure Studies. Rome.

FMH (2000) The Federal Ministry of Health National AIDS/STD Control Programme (2000) prevalence survey in Nigeria. Nigeria Journal of General Practice 1, 7-8.

Gruskin, S. (1995) Negotiating the relationship of HIV/AIDS to reproductive health and reproductive rights. The American University Law Review 44, 1191.

Gruskin, S. \& Wakhweya, A.M. (1997) A human rights perspective on HIV/AIDS in Sub-Saharan Africa. AIDS, 11 Suppl B, S159-S167.

Izugbara, C.O. \& Modo, F.N. (2007) Risks and benefits of multiple sex partnerships: beliefs of rural Nigerian adolescent males. American Journal of Men's Health 2, 77-89.

Madise, N. (2007) Reproductive health in Africa: major challenges and opportunities. Tropical Medicine and International Health 12 (Suppl. 1), 1-24.

Odusanya, O.O. \& Alakija, W. (2004 ) HIV: knowledge and sexual practice amongst students of a school of community health in Lagos, Nigeria. African Journal of Medicine and Medical Sciences 33, 45-49.

Swaminathan, H., Bhatla, N. \& Chakraborty, S (2007) Women's Property Rights as an AIDS Response: Emerging Efforts in South Asia. ICRW-International Centre for Research on Women, 12 p.

Taffa, N. Klepp, K.I., Sundby, J. \& Bjune, G. (2002) Psychosocial determinants of sexual behaviour and condom use intention among youth in Addis Ababa, Ethiopia. International Journal of STD\& AIDS 13, 714-719.

Umeasiegbu, R.N. (1977) The Way We Lived: Igbo Customs and Stories. Heinemann Publishing Company, London.

UN (2004) Women and HIV/AIDS: Advocacy, Prevention and Empowerment. http://www.icrw. org

Whiteside, A. (2002)Poverty and HIV/AIDS in Africa. Third World Quarterly 23, 313- 332.

World Bank (2003) HIV/AIDS and Gender Equity. Gender and Development Briefing Notes. World Bank, Washington, D C.

Zulu, E., Dodoo, F.N. \& Ezeh. A.C. (2002) Sexual risk taking in the slums of Nairobi, Kenya 199398. Population Studies 56, 311-323. 